\title{
Solid State X-ray Fluorescence Spectrometry at the J Paul Getty Museum 1977-78
}

John Twilley ${ }^{1}$

1. Department of Materials Science and Chemical Engineering, Stony Brook University, Stony Brook, NY, USA

Shortly before his death in 1976, J. Paul Getty purchased a solid-state, energy dispersive X-ray spectrometer on behalf of the fledgling scientific laboratory of the newly opened museum in Malibu, known today as the Getty Villa. Attention had recently been drawn to the potential of solid-state X-ray spectrometers based on $\mathrm{Ge}$ and $\mathrm{Si}$ detectors for elemental analyses in museums through publications from Oxford and elsewhere.[1,2] Getty's purchase came at the instigation of his first formally trained conservator, David Rinne, who saw the establishment of a scientific lab as an early step in professionalization of a conservation department for the new museum. It was the first instrument of its kind in an art museum laboratory in the western U.S. and over the next two years, it played a pivotal role in the analysis of ancient artifacts, European paintings, and decorative arts, and in support of ongoing conservation activities. The Princeton Gamma Tech instrument, originally configured as a detector for electron beam-excited X-ray spectrometry in the scanning electron microscope, employed a $10 \mathrm{~mm}^{2}$ $\mathrm{Si}(\mathrm{Li})$ detector and was initially equipped with sealed radioisotope sources of primary radiation in the form of short-lived ${ }^{55}$ iron and ${ }^{109}$ cadmium. Following creation of a radiation safety plan and the relevant licensing improvements, a long-lived, annular source containing ${ }^{241}$ americium was acquired, increasing the primary flux and improving sensitivity for transition metals through excitation by the $59.5 \mathrm{keV}$ emission line. The instrument was building-portable and the use of a non-volatile ferrite core memory array made rebooting after transport unnecessary. The use of monochromatic excitation yielded spectra with very low background, lacking the scattered continuum radiation that characterizes X-ray tubeexcited spectra. In addition to in-house analyses, the instrument made it possible for the staff scientist and conservators to engage in a number of conservation outreach efforts, such as support for the stabilization of the Watts Towers, for UCLA archaeologists working on Native American sites, and artifact identification for the US Customs Service. Museum works investigated by the author during this period included paintings by Rogier van der Weyden, Fillipo Lippi, Masaccio, Rembrandt, Gentile da Fabriano, and Robert Campin; furniture by Bernard van Risenburgh and Andre-Charles Boulle, and a number of Greek, Roman and Egyptian bronzes. Solid-state X-ray spectrometry was also employed by the author along with elemental mapping for diverse decorative layers such as paint cross sections and Greek black-figure ceramic glazes using SEM facilities at the Scripps Institute of Oceanography, La Jolla. In cooperative projects, the PGT instrument at the Getty provided non-sampling trace element analysis by which obsidian artifacts from Lake County, California, were assigned a geological provenance on behalf of Caltrans. It formed the basis for development of a new microsampling approach to quantitative analysis of ternary gold-silver-copper alloys of Pre-Columbian tumbaga that circumvented the effects of surface-depletion gilding employed for these Muisca artworks.[3] Although short-lived, and limited in scale during these years that preceded the legal resolution of challenges to Getty's bequest, the seed of an idea had been planted within the institution for the role that scientific analysis should play in the investigation of artists' materials, as well as the role that the Getty bequest could have in supporting conservation efforts outside the walls of the institution. Upon establishment of the Getty Trust in 1982, a new entity was created alongside the museum, the Getty Conservation Institute, to contain a scientific department that would serve both the needs of the Museum and external collaborative research programs envisioned as the main role of GCI. 
References:

[1] E T Hall, F Schweizer, and P A Toller, Archaeometry 15, \#1 (1973), p. 53

[2] V F Hanson, Applied Spectroscopy 27, \#5, (1973), p. 309

[3] J Twilley, in "Actes du XXeme Symposium International d'Archeometrie", ed. L Langouet, (University de Rennes, Rennes, 1980), Vol. III, p. 303

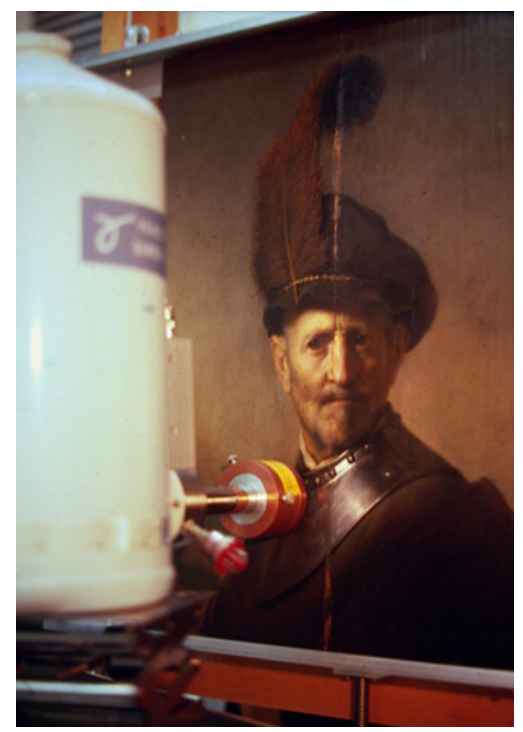

Figure 1. "An Old Man in Military Costume" (Rembrandt Harmensz van Rijn, about 1630-1631, Oil on panel, The J. Paul Getty Museum, 78.PB.246), undergoing elemental analysis by X-ray spectrometry using a $1 \mathrm{mCi}$ annular ${ }^{241} \mathrm{Am}$ source and $\mathrm{Si}(\mathrm{Li})$ detector, after removal of overpaint in 1978.

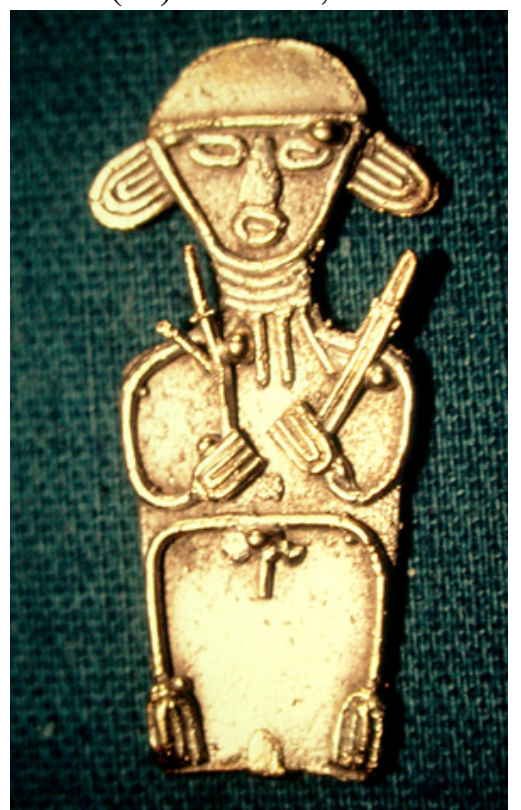

Figure 2. A gold alloy votive offering or "tunjo" of the Muisca culture from the group analyzed, depicting a male figure carrying implements, height: approx. $4 \mathrm{~cm}$ 